\title{
Microwave-assisted synthesis of 3,4-Dihydropyrimidin-2(1H)-ones using acid-functionalized mesoporous polymer
}

\author{
Bishwajit Changmai, ${ }^{a}$ Kalyani Rajkumari, ${ }^{\mathrm{ab}} \mathrm{b}$ Diparjun Das ${ }^{\mathrm{a}}$ and Lalthazuala Rokhum, ${ }^{\mathrm{a}, \mathrm{c} *}$ \\ ${ }^{a}$ Department of Chemistry, National Institute of Technology Silchar, Assam-788010, India \\ ${ }^{b}$ Department of Chemistry, Duliajan College, Duliajan, Assam-786602, India \\ 'Department of Chemistry, University of Cambridge, Lensfield Road, Cambridge CB2 1EW, \\ UK.
}

Corresponding author. Tel.: +91 3842 242915; fax: +91 3842-224797;

Email address: rokhum@che.nits.ac.in;

\begin{abstract}
Synthesis and application of acid-functionalized mesoporous polymer catalyst for the synthesis of 3,4-Dihydropyrimidin-2(1H)-ones via Biginelli condensation reaction under microwave irradiation is investigated. Several analytical techniques such as FT-IR, BET, TEM, SEM and EDX were employed to characterize the synthesized polymeric catalyst. High acidity $(1.15 \mathrm{mmol}$ $\left.\mathrm{g}^{-1}\right)$, high surface area $\left(90.44 \mathrm{~m}^{2} \mathrm{~g}^{-1}\right)$ and mesoporous nature of the catalyst effectively promoted the synthesis of 3,4-Dihydropyrimidin-2(1H)-ones. Microwave irradiation shows higher yield (89-98 \%) as compared to conventional heating (15-25 \% yield) under our optimized reaction conditions such as 1:1:1.2 molar ratio of aldehyde/ethylacetoacetate/urea, catalyst loading of 6 wt.\% (with respect to aldehyde), the temperature of $80^{\circ} \mathrm{C}$ and microwave power of $50 \mathrm{~W}$. The synthesized Biginelli products were fully characterized by ${ }^{1} \mathrm{H}$ and ${ }^{13} \mathrm{C}$ NMR. The reusability of the catalyst was investigated up to 5 successive cycles and it showed great stability towards the synthesis of 3,4-Dihydropyrimidin-2(1H)-ones without any significant depreciation in yields.
\end{abstract}

Keywords: Multicomponent reaction; Biginelli reaction; Microwave-irradiation; Dihydromidinones; Polymer. 


\section{Graphical Abstract}

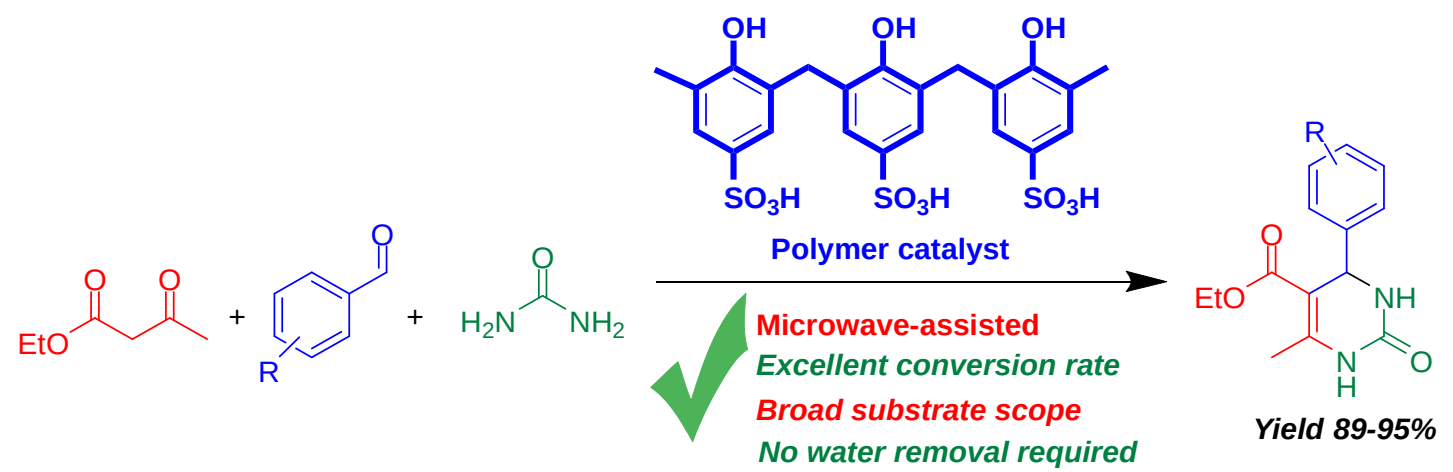

\section{Introduction}

Multicomponent reactions (MCRs) are attracting utmost attention as it promotes the formation of several bonds in a single process with diverse advantages such as simple procedure, energy and time efficient, easy purification process, etc. limits the waste generation. ${ }^{1,2}$ Besides, MCR can be considered a useful tool for synthesizing diverse chemical compounds with a complex structure. Biginelli reaction is the top-ranked example of MCR for the synthesis of dihydropyrimidinones (DHPMs), exhibited various pharmacological and therapeutic properties such as antibacterial, antiviral, antifungal, etc. ${ }^{3,4,5}$

Classical Biginelli reaction involves one pot condensation between aldehyde, dicarbonyl compound and urea/thiourea in the presence of homogeneous acid catalyst $\mathrm{HCl}$, which exhibited some serious drawbacks such as harsh reaction conditions, low yield and selectivity, require longer time, difficulty in product purification, non-recyclable etc. ${ }^{6,7}$ In this regard, solid catalyst can compensate the drawbacks associated with homogeneous catalyst as they are non-toxic, easy to handle, high selectivity, easy separation process and reusable. ${ }^{9,10}$ Numerous solid acid catalysts such as $\mathrm{ZrO}_{2}-\mathrm{SO}_{3} \mathrm{H},{ }^{11} \mathrm{HY},{ }^{12}$ alumina sulfuric acid, ${ }^{13}$ tungstate sulfuric acid, ${ }^{14}$ ompg- $\mathrm{C}_{3} \mathrm{~N}_{4}{ }^{15}$ $\mathrm{FeCl}_{3} @ S i-M C M-41^{16}$ etc. have been utilized in Biginelli reaction to produce DHPMs. However, many of these catalysts preparation involves multi-steps, high temperature, longer time and toxic chemicals, limiting their application as a green catalyst. ${ }^{17,6}$ Recently, polymer-based solid catalysts are attracting immense attention in the field of MCRs because of their greener 
approaches. To date, a wide range of polymer-based catalysts has been employed in the Biginelli reaction, such as polyaniline supported $\mathrm{FeCl}_{3,}{ }^{18} \mathrm{PEG}-\mathrm{SO}_{3} \mathrm{H},{ }^{19} \mathrm{PS}-\mathrm{PEG}-\mathrm{SO}_{3} \mathrm{H},{ }^{20} \mathrm{PSBIL} @$ polymer ${ }^{21}$ etc. However, these catalysts require prolonged reaction time to obtain good product yield in the conventional heating technique. In this context, the microwave irradiation technique can be utilized to synthesize DHMPs as it involves rapid and uniform heating, leading to the improvement in the reaction rate and selectivity to a greater extent compared to conventional heating. ${ }^{22,23}$ Besides, aldehyde, dicarbonyl compounds, and urea are excellent absorbers of microwave radiation; it is a perfect choice to utilize the microwave irradiation technique for Biginelli reaction. ${ }^{24}$ To date, a few catalysts are available on the utilization of microwave irradiation in Biginelli reaction using a solid acid catalyst such as ferric chloride hexahydrate, ${ }^{25}$ $\mathrm{FeCl}_{3}$ supported nanopore silica, ${ }^{26} \mathrm{Cu}(\mathrm{OTf})_{2}{ }^{27}$ etc.

In view of the above fundamental concepts and our continuous effort to develop an economical, efficient, and greener solid catalyst ${ }^{27,28,29}$, we, for the first time reporting the microwave-assisted synthesis of DHPMs using acid-functionalized mesoporous polymer (AFMP) catalyst via Biginelli approach.

\section{Experimental}

\subsection{Materials}

Phenolsulfonic acid and formaldehyde (37\%) were purchased from Sigma-Aldrich. Glycerol and acetone were purchased from Merck, India. Deionized water was obtained from Department of Chemistry, National Institute of Technology, Silchar, India.

\subsection{Catalyst preparation}

The polymer catalyst was prepared from reported procedure ${ }^{30}$ with slight modification. $7.15 \mathrm{~mL}$ $37 \%$ aqueous formaldehyde solution $(72.5 \mathrm{mmol}), 2.52 \mathrm{~g}(14.5 \mathrm{mmol})$ of phenolsulfonic acid were mixed with $7.25 \mathrm{~mL}$ of deionized water in an autoclave and kept in an oven at $110{ }^{\circ} \mathrm{C}$ for 6 h. After cooling, the solid mass was first washed with methanol and acetone to remove unreacted formaldehyde and phenolsulfonic acid. The resultant product was dried in a vacuum oven at 60 ${ }^{\circ} \mathrm{C}$ for $8 \mathrm{~h}$. A reddish-brown polymer was obtained after the drying process (Scheme 1). 


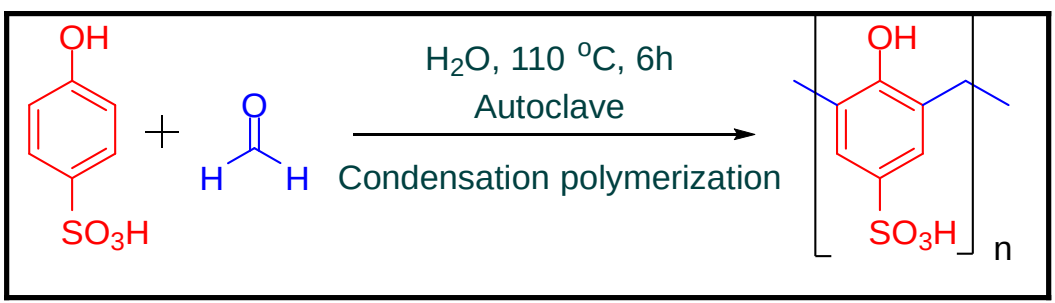

Scheme 1: Synthesis of AFMP by condensation polymerization.

\subsection{Catalyst characterization}

After successful synthesis of the catalyst, to examine the formation of the desired product, various characterization tools have been utilized such as scanning electron microscopy (SEM), energy-dispersive X-ray spectroscopy (EDX), transmission electron microscopy (TEM), BET, and fourier transform-infrared spectroscopy (FT-IR). SEM analysis and EDX was performed in JEOL model JSM - 6390LV instrument; operating conditions: $80 \mathrm{~mA}$ beam current, $20 \mathrm{kV}$ and $1500 \mathrm{X}$ magnification power. The samples were first dispersed in ethanol via ultrasonication and dried in an oven over a copper grid, and finally, the copper grid was placed in SEM. EDX analysis was performed on the same instrument by changing it to EDX mode with 0.28 sr of solid angle. HR-TEM (high-resolution transmission electron microscope) was performed on JEOL/JEM 2100 instrument with a magnifying power of 2000 X-1500000 X; condition: 200 kV voltage. The samples were dispersed in ethanol and dried in the oven over a copper grid, and placed on TEM. FTIR analysis was performed on Bruker instrument. BET was performed on Micromeritics ASAP 2010 surface area and porosity analyzer.

\subsection{Catalyst activity test}

Aldehyde (1 mmol), ethylacetoacetate $(1 \mathrm{mmol})$, urea $(1.2 \mathrm{mmol})$, and $6 \mathrm{wt}$ \% polymer catalyst (wrt aldehyde) were taken in a glass vial, placed in the microwave reactor, and irradiated for 1020 min with $50 \mathrm{~W}$ ample power and $80^{\circ} \mathrm{C}$. The progress of the reaction was monitored by thin layer chromatography (TLC). After completing the reaction, the solid product was dissolved in ethanol, filtered the catalyst, and removed the ethanol by using a rotary evaporator followed by washing with deionized water. Finally, the washed product was recrystallized in hot ethanol and dried in vacuum oven at $60{ }^{\circ} \mathrm{C}$ for $6 \mathrm{~h}$.

\subsection{Characterization of DHPMs}


${ }^{1} \mathrm{H}$ and ${ }^{13} \mathrm{C}$ NMR (Nuclear magnetic resonance) was performed to examine the successful formation of diverse DHPMs. ${ }^{1} \mathrm{H}$ and ${ }^{13} \mathrm{C}$ NMR were taken on JEOL ECZR series instrument with a spectrometer frequency of $600 \mathrm{MHz}$, tetramethyl silane (TMS) was used as an internal standard and DMSO- $\mathrm{d}_{6}$ as solvent.

\section{Results and discussions}

\subsection{Catalyst characterization}

At first, FT-IR spectroscopic analysis was performed on the polymer catalyst to investigate its functionality. The IR spectra in the Fig. 1 shows multiple distinguished peaks for different functional groups present in the catalyst. The absorption peak at $1032 \mathrm{~cm}^{-1}$ can be attributed to the symmetric stretching of $\mathrm{S}=\mathrm{O}$ bond of $\mathrm{SO}_{3} \mathrm{H}$ functionality. ${ }^{31,30}$ While the bending and stretching vibrations of $-\mathrm{OH}$ bond shows absorption band at $596 \mathrm{~cm}^{-1}$ and $3440 \mathrm{~cm}^{-1}$, on the other hand, the peak at $1223 \mathrm{~cm}^{-1}$ can be assigned to the aromatic $-\mathrm{OH}$ stretching. ${ }^{32}$ The absorption bands at $1471 \mathrm{~cm}^{-1}$ and $1648 \mathrm{~cm}^{-1}$ suggests $\mathrm{C}=\mathrm{C}$ stretching vibration of benzene ring of the polymeric backbone. ${ }^{33}$

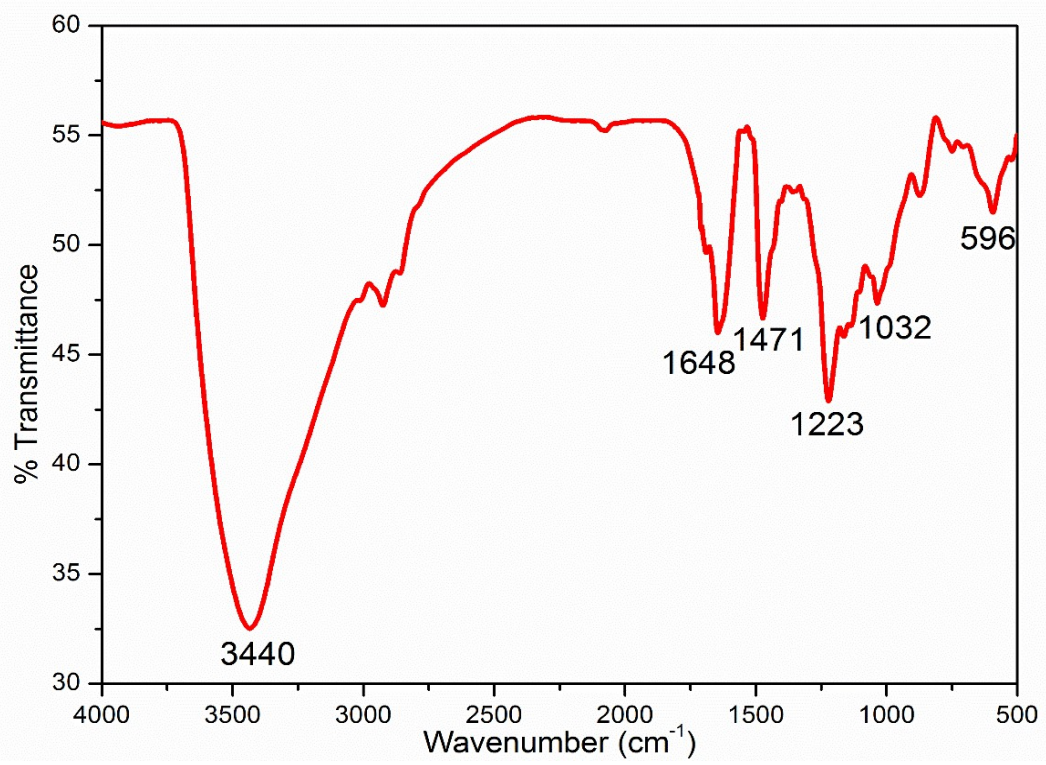

Fig. 1: FT-IR spectra of AFMP catalyst

Another important aspect of heterogeneous catalysts is their porosity. The nature of pores and their sizes can be investigated with the help of $\mathrm{N}_{2}$ adsorption-desorption analysis by BET model. The BET adsorption-desorption isotherm of the polymer catalyst is shown in Fig. 2 referring 
characteristic features of type-IV hysteresis loop which suggests capillary condensation in mesopores. The surface area of the catalyst was found to be $90.44 \mathrm{~m}^{2} / \mathrm{g}$ with average pore size of $5.2 \mathrm{~nm}$. The pore-size distribution curve (Fig. 2 (inset)) shows uniform sizes of the porous structures.

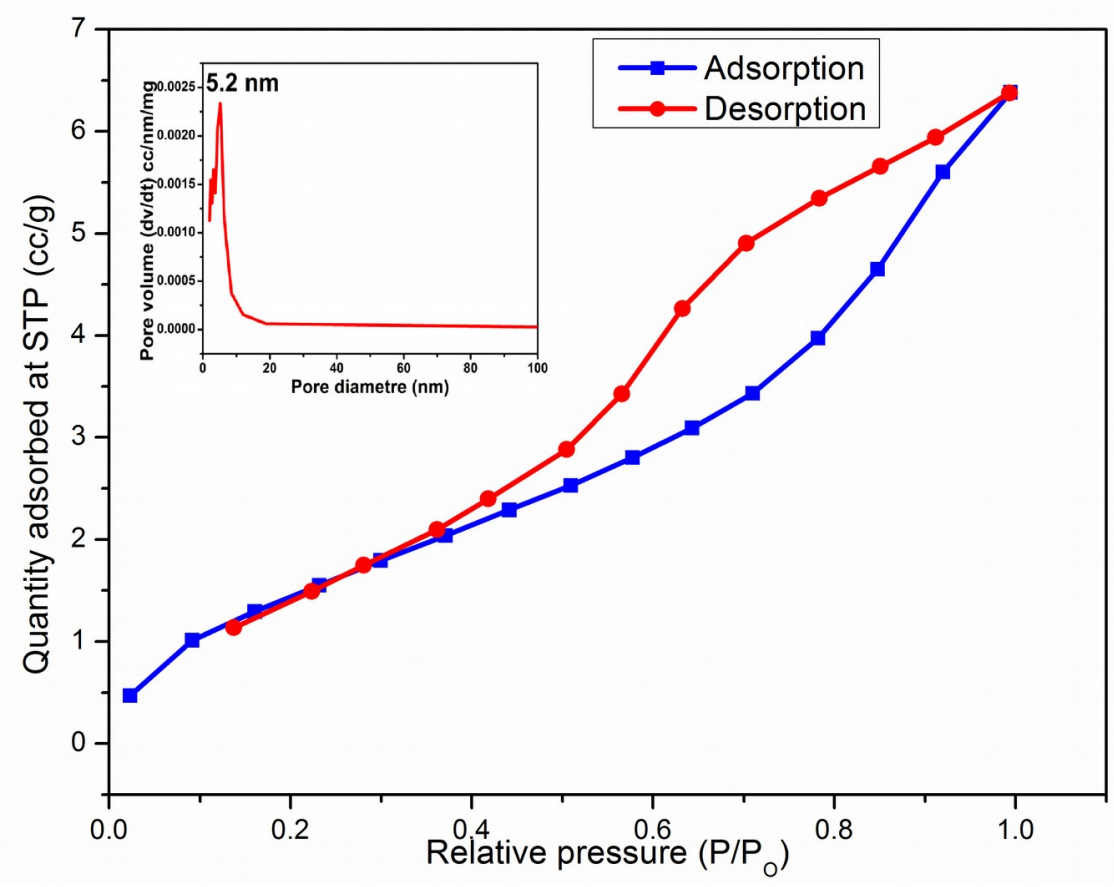

Fig. 2: $\mathrm{N}_{2}$ adsorption-desorption isotherm and pore distribution curve (inset) of AFMP.

SEM and TEM analysis was performed to investigate the surface morphology and structure of the catalyst. The SEM images (Fig. 3a, b) displayed an irregular sheet-like surface of the catalyst, whereas the TEM images (Fig. 3c, d) displayed the porous structure with uniform particle arrangement, which is good agreement with the $\mathrm{N}_{2}$ adsorption-desorption analysis. The average particle size of the catalyst was found to be $7-8 \mathrm{~nm}$. 

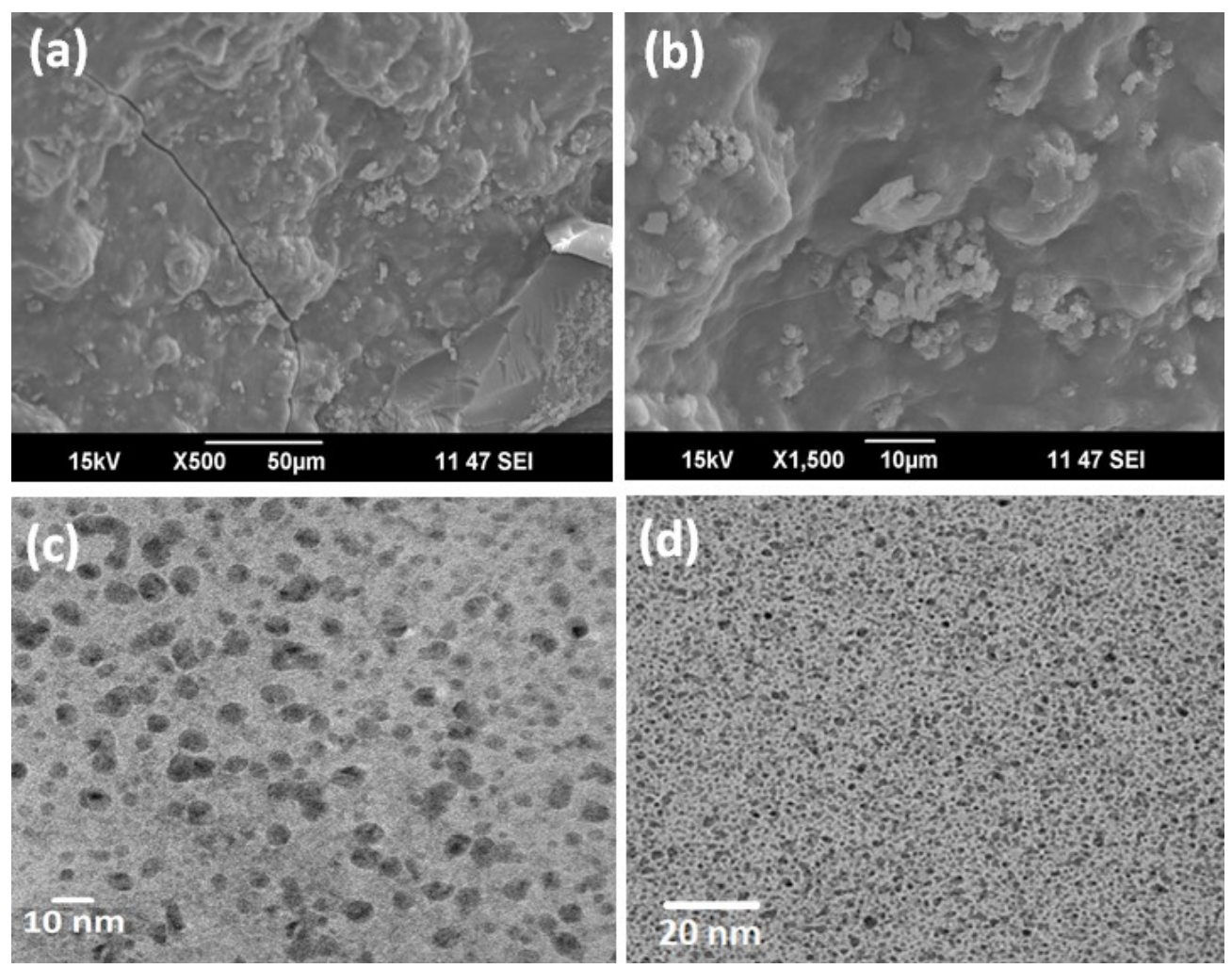

Fig. 3: SEM (a, b) and TEM (c, d) micrographs of AFMP.

EDX data (Fig. 4) showed the presence of all the desired elements such as carbon, oxygen and sulfur. The sulfur content (Fig. 4 inset) in the catalyst was found to be $3.7 \mathrm{wt}$. $\%\left(1.15 \mathrm{mmol} \mathrm{g}^{-1}\right)$, confirming the successful introduction of sulfonic acid to the polymer catalyst. The high catalytic activity of the polymer catalyst may be due to the presence of high content of sulfonic group. 


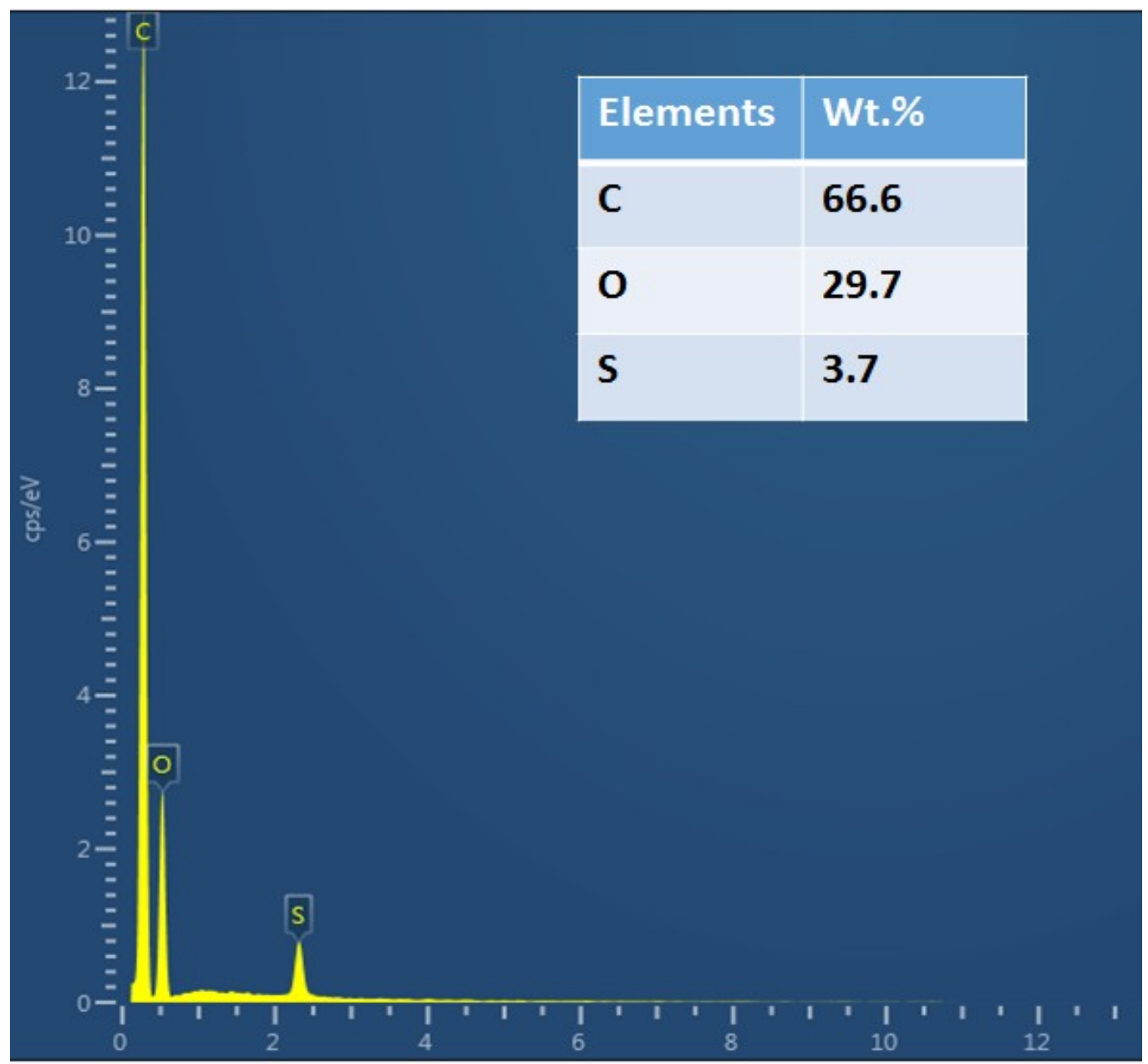

Fig. 4: EDX spectrum and the elemental composition (inset) of the catalyst

\subsection{Catalyst activity in Biginelli reaction}

After characterization, the activity of the catalyst was examined by performing Biginelli reaction. The reaction between 4-nitrobenzaldehyde, ethylacetoacetate and urea in presence of polymer catalyst under solvent-free and microwave irradiation is considered as a model reaction. It was found that, 98\% isolated yield of particular DHPMs was obtained within 10 min of reaction. Besides, the formation of a single product suggested that the polymer catalyst presence's reaction is highly selective. The comparison between the microwave irradiation and conventional heating technique for the model reaction revealed that microwave irradiation improves the yield in many-fold than the conventional heating. The effect of solvent on the model reaction was examined by performing the reaction under various solvents such as $\mathrm{EtOH}, \mathrm{MeOH}, \mathrm{CH}_{3} \mathrm{COCH}_{3}$, 
THF and $\mathrm{CH}_{3} \mathrm{CN}$ (Fig. 5a). However, the best result was obtained in terms of reaction time and isolated yield under solvent-free condition.

The effect of catalyst loading (Fig. 5b) on the model reaction was tested by varying the catalyst amount from 2-8 wt.\% using the reaction conditions: 1:1:1.2 4-nitrobenzaldehyde/ethylacetoacetate/urea molar ratio, $80{ }^{\circ} \mathrm{C}$ temperature, $10 \mathrm{~min}$ time and 50 $\mathrm{W}$ microwave power. The increase in catalyst amount initially increased the yield of the DHPM, attributed to the increase in the catalyst active sites. ${ }^{34,35}$ The highest yield of $98 \%$ was obtained when the catalyst amount was increased to $6 \mathrm{wt}$. \%, however, further increase in the catalyst amount led to the depletion of DHPMs yield as large amount of catalyst makes the reaction mixture more viscous, hence inhibits the interaction between the reactants and catalyst active sites. ${ }^{36,37}$

Furthermore, the reaction temperature was varied from $35-95{ }^{\circ} \mathrm{C}$ to examine its effect on the model reaction (Fig. 5c). The increase in temperature initially increased the yield as Biginelli reaction is an endothermic reaction..$^{38}$ The highest yield of $98 \%$ was obtained at $80{ }^{\circ} \mathrm{C}$; no further improvement in yield was observed beyond $80{ }^{\circ} \mathrm{C}$. Finally, the effect of microwave power was also tested by varying from 30-70 W (Fig. 5d). Initially, the increase in yield was observed when microwave power increased as high microwave power resulted in efficient collision between the reactants and the catalyst active sites. ${ }^{39}$ The highest yield of $98 \%$ was obtained at microwave power, however, further increase in microwave power led to the slight depletion in yield as at very high power temperature of the reaction mixture increased instantaneously, leading to the violent collision between the reactants and catalyst active sites. ${ }^{40}$ 

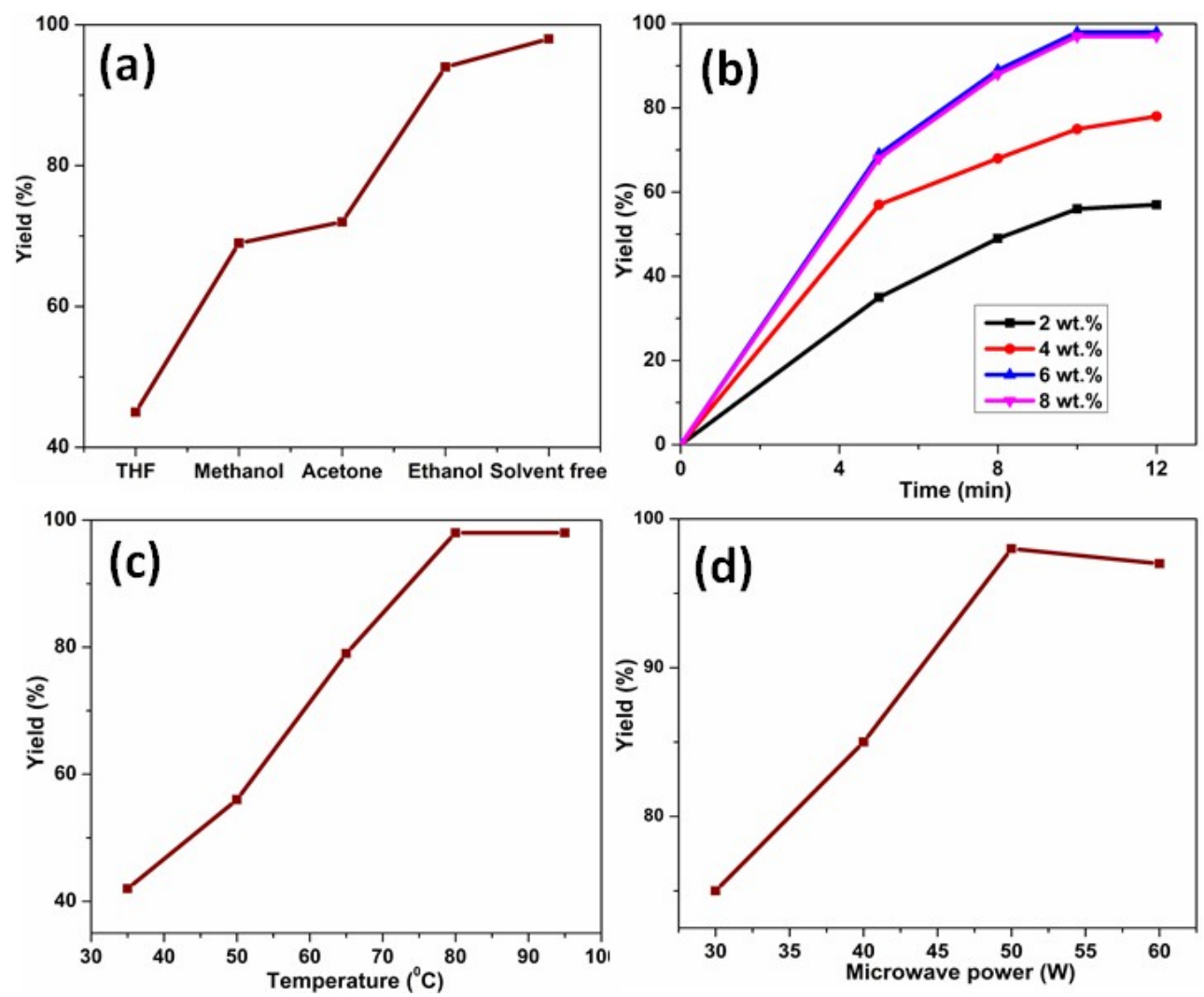

Fig.5: The effect of solvents, catalyst loading, reaction temperature and microwave power on Biginelli reaction. Reaction conditions: 4nitrobenzaldehyde/ethylacetoacetate/urea molar ratio of 1:1:1.2 and reaction time of $10 \mathrm{~min}$.

After attaining the optimization conditions, the reaction was generalized for various aromatic aldehydes to establish our catalyst scope (Scheme 2). The reaction between various aldehydes with ethylacetoacetate and urea showed good to excellent yield in acid-functionalized polymer catalyst presence, as shown in Table 1 . Table 1 shows that the aromatic aldehyde having an electron-withdrawing group (such as $-\mathrm{NO}_{2}$ group) showed a faster reaction rate and excellent yield, whereas the electron-donating groups (such as $-\mathrm{OCH}_{3}$ group) in the aldehyde took a long time for complete conversion. Besides, our synthesized catalyst is tolerant of various functional groups such as $-\mathrm{NO}_{2},-\mathrm{Cl},-\mathrm{OCH}_{3}$, $-\mathrm{OH}$, etc.

Table 1: Biginelli reaction over acid-functionalized polymer catalyst using diverse aromatic aldehydes. Reaction conditions: Aldehyde/ethylacetoacetate/urea molar ratio of 1:1:1.2, 6 wt. $\%$ catalyst loading, $80{ }^{\circ} \mathrm{C}$ reaction temperature, $50 \mathrm{~W}$ microwave power, and 10-20 min 


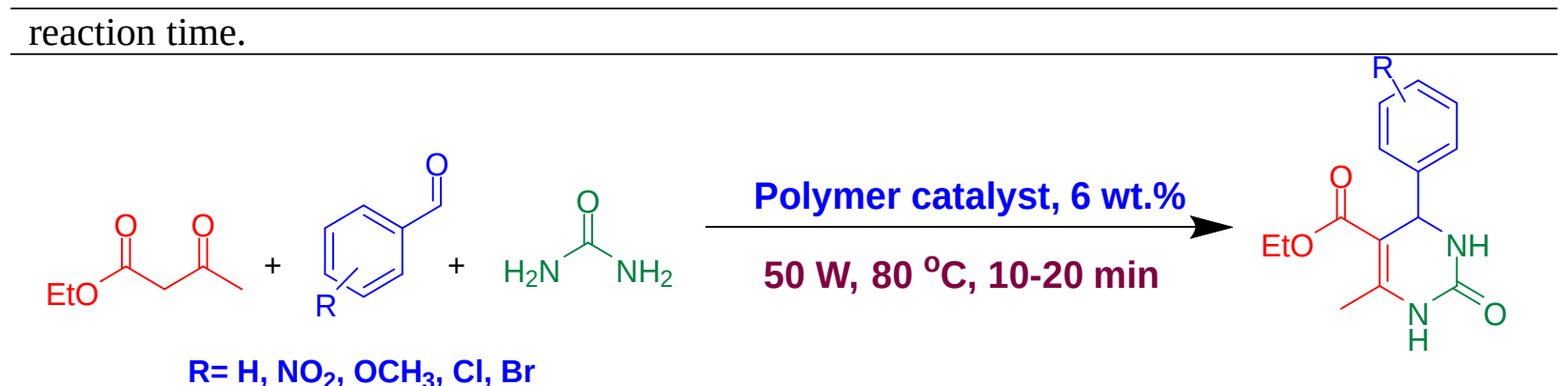

Scheme 2: Synthesis of DHPMs using AFMP.

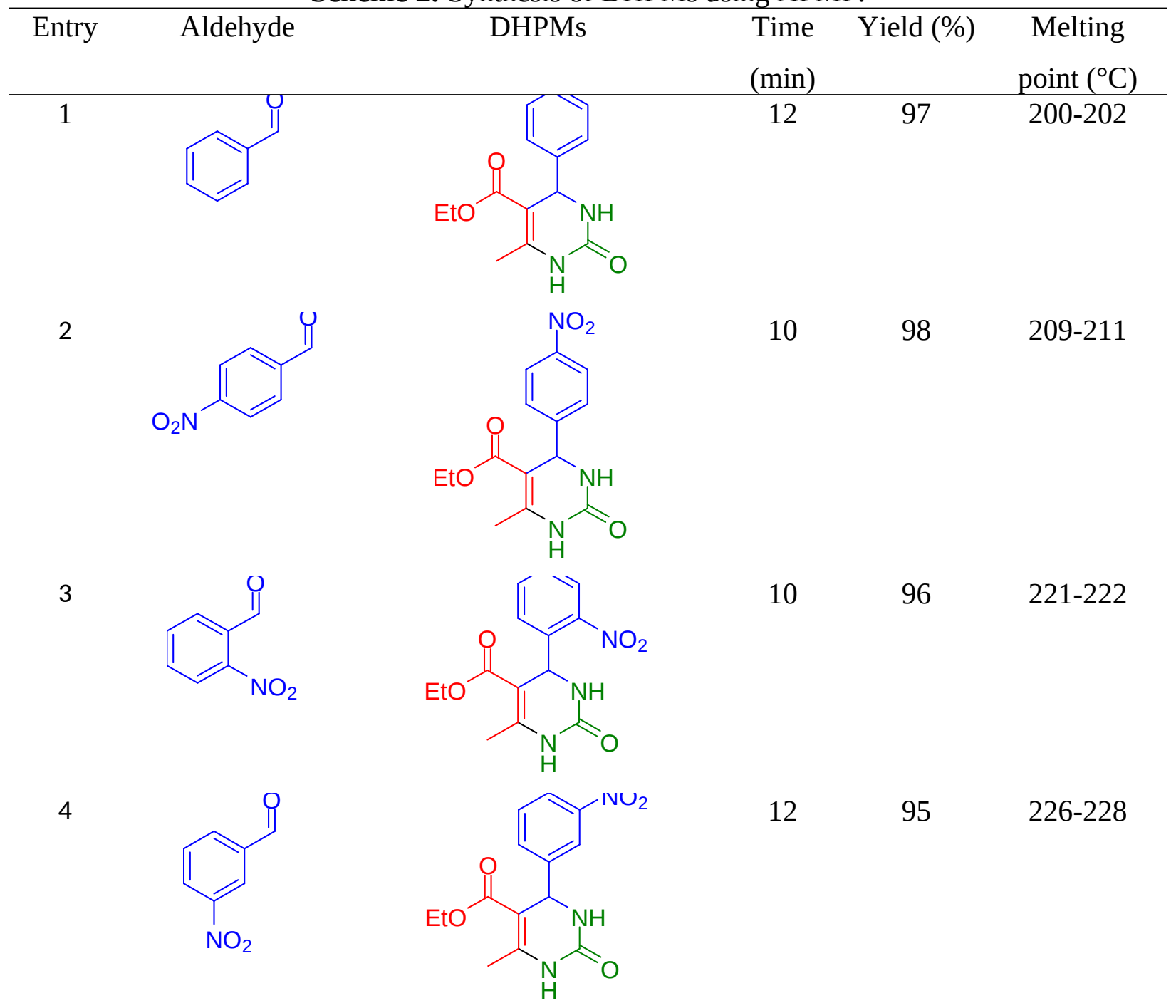


5<smiles>COc1ccc(C=O)cc1</smiles>

6<smiles>COc1ccccc1C=O</smiles>

7<smiles>O=Cc1ccc(Br)cc1</smiles>

8<smiles>O=Cc1ccc(Cl)cc1</smiles>

9<smiles>O=Cc1ccccc1Cl</smiles><smiles>CCOC(=O)C1=C(C)NC(=O)NC1c1ccc(OC)cc1</smiles><smiles>CCOC(=O)C1=C(C)NC(=O)NC1c1ccc(Br)cc1</smiles><smiles>CCOC(=O)C1=C(C)NC(=O)NC1c1ccc(Cl)cc1</smiles>

16

92

$179-180$

18

90

214-215

\subsection{DHPMs characterization}

${ }^{1} \mathrm{H}$ and ${ }^{13} \mathrm{C}$ NMR was performed to confirm the formation of desired DHPMs. The NMR data are presented below: 
Appearance: White solid. Melting point: 200-202 ${ }^{\circ} \mathrm{C}$; ${ }^{1} \mathrm{H}$ NMR (600 MHz, DMSO- $\left.\mathrm{d}_{6}\right) \delta 9.21$ (s, 1H), 7.63 (s, 1H), 7.36-7.30 (m, 2H), 7.22-7.19 (m, 3H), 5.10 (d, 1H), 3.98 (q, 2H), 2.21 (s, 3H), 1.00 (t, 3H); ${ }^{13} \mathrm{C}$ NMR (75 MHz, DMSO-d 6 ) $\delta 165.1,151.9,148.2,145.0,128.2,127.0,126.5$, 99.0, 59.1, 54.0, 18.0, 14.1.

5-Ethoxycarbonyl-6-Methyl-4-(4-nitrophenyl)-3,4-Dihydropyrimidin-2(1H)-One (Table 1, Entry 2)

Appearance: White solid; melting point: $209-211^{\circ} \mathrm{C}$; $1 \mathrm{H}-\mathrm{NMR}\left(600 \mathrm{MHz}, \mathrm{DMSO}-\mathrm{d}_{6}\right): \delta=9.33$ (s, 1H), 8.19 (m, 2H), 7.88 (s, 1H), 7.47-7.55 (m, 2H), 7.03-6.95 (m, 3H), $5.78(\mathrm{~s}, 1 \mathrm{H}), 3.93$ (q, 2H), 2.48 (s, 3H), 1.06 (t, 3H); ${ }^{13} \mathrm{C}-\mathrm{NMR}$ (600 MHz, DMSO-d $\left.)_{6}\right): \delta=13.01,39.22$, 58.67, 64.602, 123.26, 127.61, 130.60, 146.50, 155.85, 157.57, 157.65, 170.25.

5-Ethoxycarbonyl-6-Methyl-4-(2-nitrophenyl)-3,4-Dihydropyrimidin-2(1H)-One (Table 1, Entry 3)

Appearance: White solid; Melting point: 221-222 ${ }^{\circ} \mathrm{C} .{ }^{1} \mathrm{H}$ NMR (600 MHz, DMSO-d 6 ): $\delta 9.01$ (s, 1H), 7.25 (s, 1H), 7.18-7.23 (m, 1H), 7.12 (d, 1H), 7.02-7.06 (m, 1H), 6.98 (d, 1H), 5.45 (d, 1H), 3.81 (q, 2H), 2.22 (s, 3H), 1.04 (t, 3H); ${ }^{13} \mathrm{C}$ NMR (600 MHz, DMSO-d $\mathrm{d}_{6}$ ): $\delta$ 16.04, 19.23, 48.00, 55.12, 98.03, 111.23, 121.32, 128.02, 134.02, 149.02, 152.30, 157.01, 166.80.

5-Ethoxycarbonyl-6-Methyl-4-(3-nitrophenyl)-3,4-Dihydropyrimidin-2(1H)-One (Table 1, Entry 4)

Appearance: pale-yellow solid; Melting point: 226-228 ${ }^{\circ} \mathrm{C} .{ }^{1} \mathrm{H}-\mathrm{NMR}\left(600 \mathrm{MHz}, \mathrm{DMSO}-\mathrm{d}_{6}\right): \delta 9$. 30 (s, 1H), 8.09-8.11 (m, 2H), 7.85 (s, 1H), 7.61-7.66 (m, 2H), 5.25 (s, 1H), 3.92 (q, 2H), 2.45 (s, 3H), 1.02 (t, 3H); ${ }^{13} \mathrm{C}-\mathrm{NMR}$ (600 MHz, DMSO-d ${ }_{6}$ ): $\delta$ 164.23, 150.96, 149.32, 147.82, 146.45, 132.12, 129.92, 122.22, 119.91, 98.12, 59.35, 52.91, 17.34, 12.95.

5-Ethoxycarbonyl-6-Methyl-4-(4-methoxyphenyl)-3,4-Dihydropyrimidin-2(1H)-One (Table 1, Entry 5)

Appearance: white solid; Melting point: 200-202 ${ }^{\circ} \mathrm{C} .{ }^{1} \mathrm{H}-\mathrm{NMR}\left(600 \mathrm{MHz}, \mathrm{DMSO}-\mathrm{d}_{6}\right): \delta=9.15$ (s, 1H), 7.65 (s, 1H), 7.05-7.11 (m, 2H), 6.75-6.80 (m, 2H), 5.04 (s, 1H), 3.87-3.90 (m, 2H), 3.65 
(s, 3H), 2.20 (s, 3H), 1.05 (m, 3H); ${ }^{13} \mathrm{C}-\mathrm{NMR}$ (600 MHz, DMSO-d 6 ): $\delta=16.04,19.69$, 53.27, 55.01, 59.00, 100.01, 114.05, 127.00, 137, 148.01, 152.01, 159.00, 166.05.

5-Ethoxycarbonyl-6-Methyl-4-(2-methoxyphenyl)-3,4-Dihydropyrimidin-2(1H)-One (Table 1, Entry 6)

Appearance: White solid; Melting point: 261-262 ${ }^{\circ} \mathrm{C}$; $1 \mathrm{H}$ NMR (600 MHz, DMSO-d6) $\delta 9.07$ (s, 1H), 6.79-7.19 (m, 5H), 5.42 (s, 1H), 3.85-3.91, (m, 2H), 3.72 (s, 3H), 2.49 (s, 3H), 1.02 (t, 3H). ${ }^{13} \mathrm{C}-\mathrm{NMR}$ (600 MHz, DMSO-d $\mathrm{d}_{6}$ ): $\delta$ 168.00, 155.45, 146.21, 129.63, 126.93, 121.12, 112.04, 59.02, 54.95, 48.71, 17.23, 14.05 .

5-Ethoxycarbonyl-6-Methyl-4-(4-chlorophenyl)-3,4-Dihydropyrimidin-2(1H)-One (Table 1, Entry 8)

Appearance: white solid; Melting point: 179-180 ${ }^{\circ} \mathrm{C} .{ }^{1} \mathrm{H}-\mathrm{NMR}\left(600 \mathrm{MHz}, \mathrm{DMSO}-\mathrm{d}_{6}\right): \delta=9.32$ (s, 1H), 7.85 (s, 1H), 7.46-7.48 (m, 2H), 7.31-7.33 (m, 2H), 5.22 (s, 1H), 4.02-4.07 (m, 2H), 2.58 (s, 3H), 2.32 (s, 3H), 1.14-1.18 (m, 3H); ${ }^{13} \mathrm{C}-\mathrm{NMR}$ (600 MHz, DMSO-d 6 ): $\delta=13.98,17.71$, 53.32, 55.01, 98.79, 128.32, 128.35, 131.75, 143.64, 148.65, 151.90, 165.18.

5-Ethoxycarbonyl-6-Methyl-4-(2-chlorophenyl)-3,4-Dihydropyrimidin-2(1H)-One (Table 1, Entry 9)

Appearance: White solid; Melting point: $214-215{ }^{\circ} \mathrm{C} ;{ }^{1} \mathrm{H}-\mathrm{NMR}\left(600 \mathrm{MHz}, \mathrm{DMSO}-\mathrm{d}_{6}\right): \delta 8.89$ (s, 1H), $71.12-7.52(\mathrm{~m}, 4 \mathrm{H}), 5.82(\mathrm{~s}, 1 \mathrm{H}), 5.75$ (s, 1H), 3.95 (q, 2H), 2.45 (s, 3H), 1.07 (t, 3H); ${ }^{13} \mathrm{C}-$ NMR (600 MHz, DMSO-d $_{6}$ : $\delta$ 165.71, 154.02, 149.01, 140.05, 133.46, 130.23, 129.23, 128.14, 99.12, 60.12, 52.40, 19.25 .

\section{Catalyst reusability}

Recyclability and reusability are significant factors for assessing a heterogeneous catalyst. The AFMP catalyst's reusability was examined by carrying out successive reactions using the same catalyst and recovering it from reaction mixture. After each cycle, the catalyst is separated from the reaction crude by filtration. The catalyst is then washed with hexane and chloroform by the shrinking-relaxing method and finally dried under reduced pressure in oven at $60{ }^{\circ} \mathrm{C}$. The results of five catalytic runs are presented in Fig. 6 which clearly shows that the catalyst activity 
remains almost unaffected even after 5th cycle. At the end of 5th catalytic cycle, 85\% product yield was obtained which suggests excellent recyclability and reusability of AFMP catalyst.

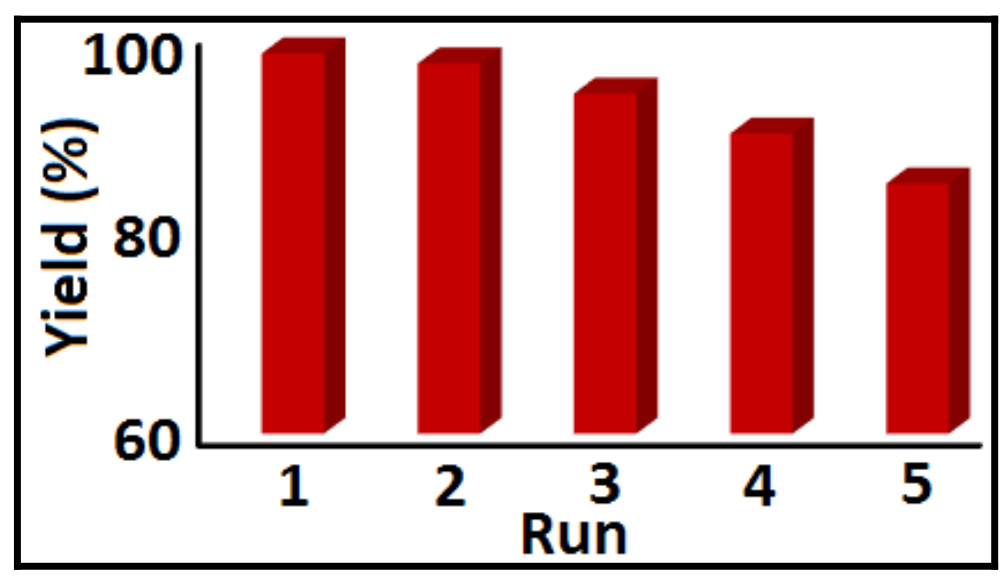

Fig. 6: Reusability test of the catalyst. Reaction conditions:

\section{1:1:1.2 of 4-nitrobenzaldehyde/ethylacetoacetate/urea}

molar ratio, $6 \mathrm{wt}$. \% catalyst loading, $50 \mathrm{~W}$ microwave power, $80^{\circ} \mathrm{C}$ temperature and $10 \mathrm{~min}$ time.

The recovered catalyst after the $5^{\text {th }}$ cycle was analyzed by SEM, TEM and EDX to examine the change in surface morphology, structure and elemental composition of the catalyst. SEM micrographs (Fig. 7a, b) showed irregular and rough surface morphology of the catalyst, whereas TEM micrographs (Fig. 7c, d) showed that the uniform arrangement and porous structure of the catalyst remain intact. However, EDX elemental composition analysis (Fig. 8) revealed that the sulfur content is decreased from 3.7 wt.\% to 2.8 wt.\%, suggesting the slight leaching of the catalyst active sites. 

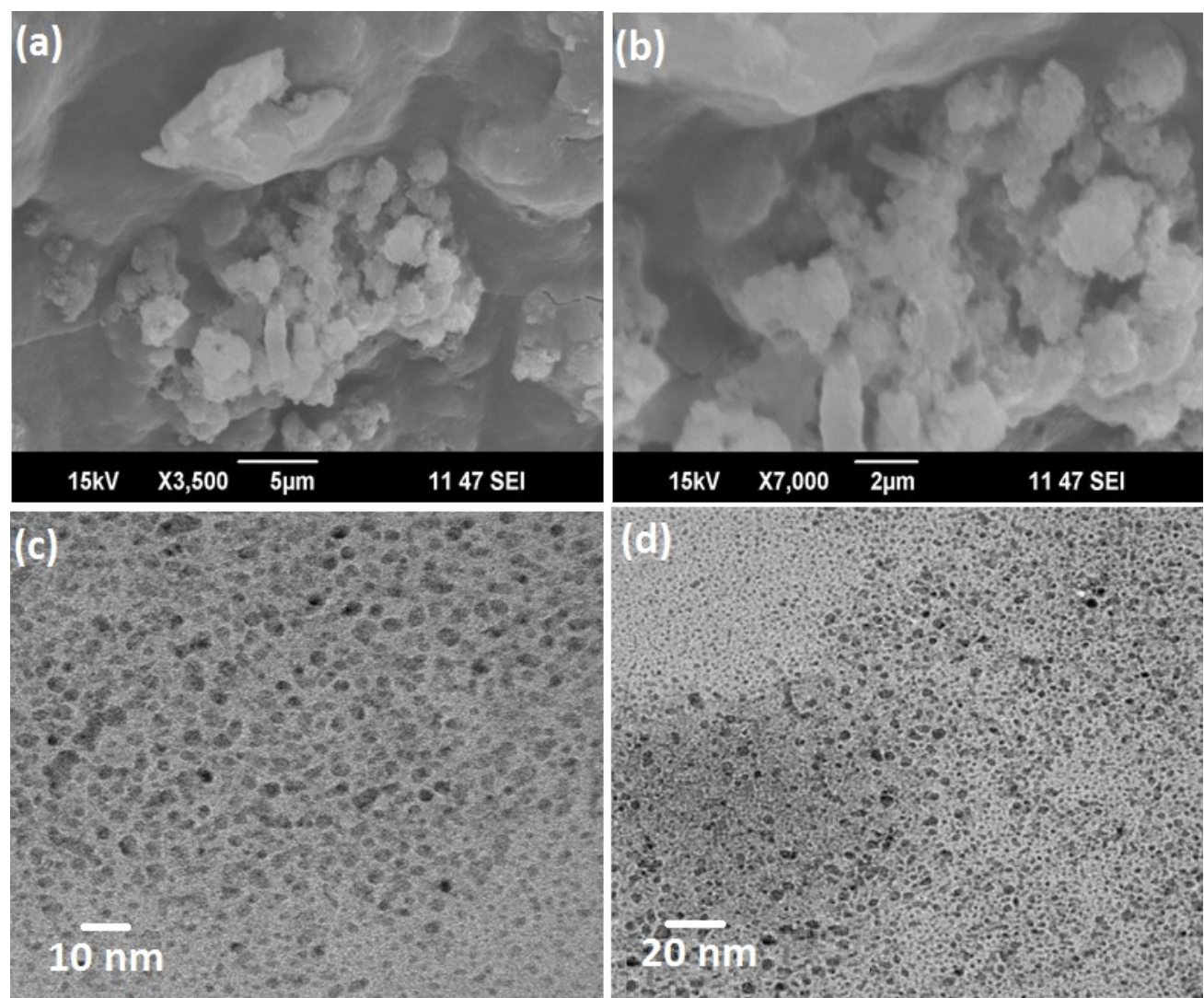

Fig. 7: SEM (a, b) and TEM (c, d) micrographs of recovered catalyst after the $5^{\text {th }}$ cycle.

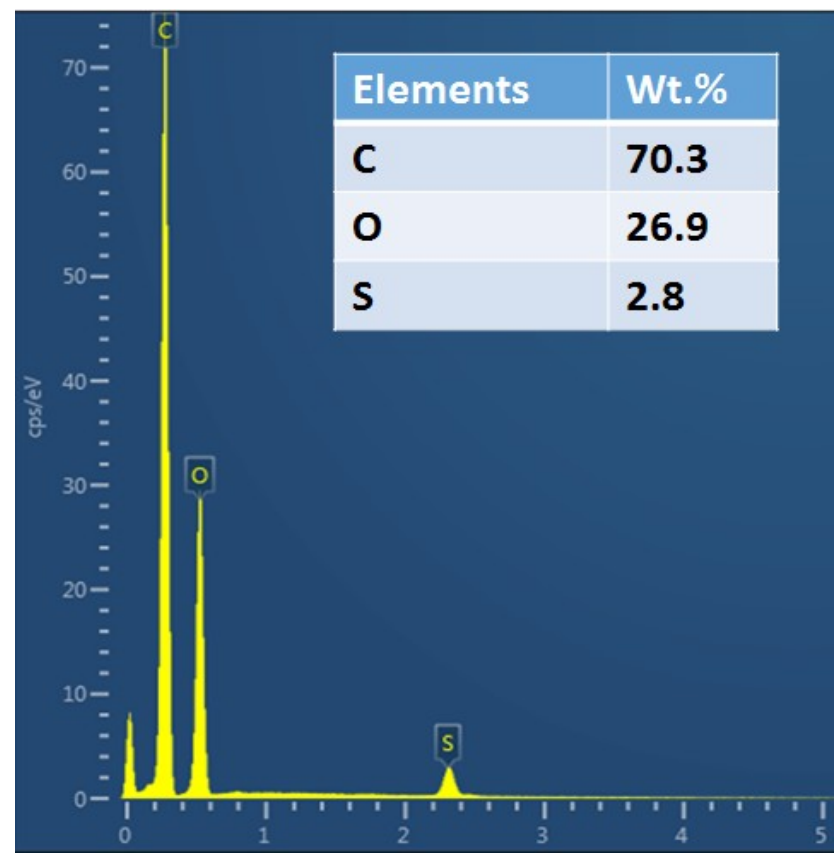

Fig. 8: EDX spectrum and elemental 
composition (inset) of the recovered catalyst

after $5^{\text {th }}$ cycle.

\section{Conclusion}

In summary, we have successfully utilized microwave-assisted AFMP catalyzed the synthesis of DHPMs under solvent-free condition via Biginelli approach. This advanced method not only maintains the simplicity in operational condition, but also tolerant to diverse functional groups and showed good to excellent DHPMs yield in a very short period of time. Besides, the catalyst is recyclable and reusable up to 5 consecutive reaction cycles with no significant loss in catalytic activity. The high catalytic activity, easy preparation, and separation process make it an excellent solid catalyst for the synthesis of DHPMs.

\section{Acknowledgment}

The authors thank SERB, India (Grant No. SB/EMEQ-076/2014 and SB/FT/CS-103/2013) for funding our work. SAIF NEHU, STIC Cochin, CSIR-NEIST were thankfully acknowledged for analysis.

\section{References}

(1) Touré, B. B.; Hall, D. G. Natural Product Synthesis Using Multicomponent Reaction Strategies. Chem. Rev. 2009, 109(9), 4439-4486. https://doi.org/10.1021/cr800296p.

(2) Shaaban, S.; Abdel-Wahab, B. F. Groebke-Blackburn-Bienaymé Multicomponent Reaction: Emerging Chemistry for Drug Discovery. Molecular Diversity. 2016, 20(1), 233-254. https://doi.org/10.1007/s11030-015-9602-6.

(3) Peng, J.; Deng, Y. Ionic Liquids Catalyzed Biginelli Reaction under Solvent-Free Conditions. Tetrahedron Lett. 2001, 42(34), 5917-5919. https://doi.org/10.1016/S00404039(01)01139-X.

(4) Suresh; Sandhu, J. S. Past, Present and Future of the Biginelli Reaction: A Critical Perspective. Arkivoc. 2012. https://doi.org/10.3998/ark.5550190.0013.103.

(5) Chen, X. H.; Xu, X. Y.; Liu, H.; Cun, L. F.; Gong, L. Z. Highly Enantioselective Organocatalytic Biginelli Reaction. J. Am. Chem. Soc. 2006, 128(46), 14802-14803. 
https://doi.org/10.1021/ja065267y.

(6) Patil, R. V.; Chavan, J. U.; Dalal, D. S.; Shinde, V. S.; Beldar, A. G. Biginelli Reaction: Polymer Supported Catalytic Approaches. ACS Comb. Sci. 2019, 21(3), 105-148. https://doi.org/10.1021/acscombsci.8b00120.

(7) Kalita, H. R.; Phukan, P. CuI as Reusable Catalyst for the Biginelli Reaction. Catal. Commun. 2007, 8(2), 179-182. https://doi.org/10.1016/j.catcom.2006.06.004.

(8) Salim, S. D.; Akamanchi, K. G. Sulfated Tungstate: An Alternative, Eco-Friendly Catalyst for Biginelli Reaction. Catal. Commun. 2011, 12(12), 1153-1156. https://doi.org/10.1016/j.catcom.2011.02.018.

(9) Changmai, B.; Pathak, G.; Anal, J. M. H.; Rokhum, L. Heterogeneous System in Organic Synthesis: A Review. Mini. Rev. Org. Chem. 2020, 17(6), 740-753. https://doi.org/10.2174/1570193X16666190830101802.

(10) Clark, J. H.; Macquarrie, D. J.; Sherwood, J. The Combined Role of Catalysis and Solvent Effects on the Biginelli Reaction: Improving Efficiency and Sustainability. Chem. - A Eur. J. 2013, 19(16), 5174-5182. https://doi.org/10.1002/chem.201204396.

(11) Kolvari, E.; Koukabi, N.; Hosseini, M. M.; Vahidian, M.; Ghobadi, E. Nano-ZrO2 Sulfuric Acid: A Heterogeneous Solid Acid Nano Catalyst for Biginelli Reaction under Solvent Free Conditions. RSC Adv. 2016, 6(9), 7419-7425. https://doi.org/10.1039/c5ra19350h.

(12) Radha Rani, V.; Srinivas, N.; Radha Kishan, M.; Kulkarni, S. J.; Raghavan, K. V. ZeoliteCatalyzed Cyclocondensation Reaction for the Selective Synthesis of 3,4Dihydropyrimidin-2(1H)-Ones. Green Chem. 2001, 3(6), 305-306. https://doi.org/10.1039/b107612b.

(13) Besoluk, S.; Kucukislamoglu, M.; Nebioglu, M.; Zengin, M.; Arslan, M. Solvent-Free Synthesis of Dihydropyrimidinones Catalyzed by Alumina Sulfuric Acid at Room Temperature. J. Iran. Chem. Soc. 2008, 5(1), 62-66. https://doi.org/10.1007/BF03245816.

(14) Karami, B.; Haghighijou, Z.; Farahi, M.; Khodabakhshi, S. One-Pot Synthesis of Dihydropyrimidine-Thione Derivatives Using Tungstate Sulfuric Acid (TSA) as a 
Recyclable Catalyst. Phosphorus, Sulfur Silicon Relat. Elem. 2012, 187(6), 754-761. https://doi.org/10.1080/10426507.2011.616562.

(15) Douzandegi Fard, M. A.; Ghafuri, H.; Rashidizadeh, A. Sulfonated Highly Ordered Mesoporous Graphitic Carbon Nitride as a Super Active Heterogeneous Solid Acid Catalyst for Biginelli Reaction. Microporous Mesoporous Mater. 2019, 274, 83-93. https://doi.org/10.1016/j.micromeso.2018.07.030.

(16) Choudhary, V. R.; Tillu, V. H.; Narkhede, V. S.; Borate, H. B.; Wakharkar, R. D. Microwave Assisted Solvent-Free Synthesis of Dihydropyrimidinones by Biginelli Reaction over Si-MCM-41 Supported FeCl3 Catalyst. Catal. Commun. 2003, 4(9), 449453. https://doi.org/10.1016/S1566-7367(03)00111-0.

(17) Shumaila, A. M. A.; Al-Thulaia, A. A. N. Mini-Review on the Synthesis of Biginelli Analogs Using Greener Heterogeneous Catalysis: Recent Strategies with the Support or Direct Catalyzing of Inorganic Catalysts. Synthetic Communications. 2019, 49(13), 16131632. https://doi.org/10.1080/00397911.2018.1536789.

(18) Patel, H. A.; Sawant, A. M.; Rao, V. J.; Patel, A. L.; Bedekar, A. V. Polyaniline Supported FeCl3: An Effective Heterogeneous Catalyst for Biginelli Reaction. Catal. Letters 2017, 147(9), 2306-2312. https://doi.org/10.1007/s10562-017-2139-9.

(19) Wang, X.; Quan, Z.; Wang, F.; Wang, M.; Zhang, Z.; Li, Z. PEG-SO3H as Catalyst for 3,4-Dihydropyrimidones via Biginelli Reaction under Microwave and Solvent-Free Conditions. Synth. Commun. 2006, 36(4), 451-456.

https://doi.org/10.1080/00397910500383519.

(20) Quan, Z. J.; Da, Y. X.; Zhang, Z.; Wang, X. C. PS-PEG-SO3H as an Efficient Catalyst for 3,4-Dihydropyrimidones via Biginelli Reaction. Catal. Commun. 2009, 10(8), 1146-1148. https://doi.org/10.1016/j.catcom.2008.12.017.

(21) Khiratkar, A. G.; Muskawar, P. N.; Bhagat, P. R. Polymer-Supported Benzimidazolium Based Ionic Liquid: An Efficient and Reusable Brønsted Acid Catalyst for Biginelli Reaction. RSC Adv. 2016, 10(8), 1146-1148. https://doi.org/10.1039/c6ra23781a.

(22) Yadav, J. S.; Subba Reddy, B. V.; Jagan Reddy, E.; Ramalingam, T. Microwave-Assisted 
Efficient Synthesis of Dihydro Pyrimidines: Improved High Yielding Protocol for the Biginelli Reaction. J. Chem. Res. - Part S 2000, 7, 354-355.

https://doi.org/10.3184/030823400103167633.

(23) Dong, J.; Liu, M.; Jiang, R.; Huang, H.; Huang, Q.; Wen, Y.; Tian, J.; Dai, Y.; Zhang, X.; Wei, Y. Ultrafast Fabrication of Fluorescent Organic Nanoparticles with AggregationInduced Emission Feature through the Microwave-Assisted Biginelli Reaction. Dye. Pigment. 2019, 165, 90-96. https://doi.org/10.1016/j.dyepig.2019.01.056.

(24) Xue, S.; Shen, Y. C.; Li, Y. L.; Shen, X. M.; Guo, Q. X. Synthesis of 4-Aryl-3,4Dihydropyrimidinones Using Microwave-Assisted Solventless Biginelli Reaction. Chinese J. Chem. 2002, 20(4), 385-389. https://doi.org/10.1002/cjoc.20020200417.

(25) Mirza-Aghayan, M.; Bolourtchian, M.; Hosseini, M. Microwave-Assisted Efficient Synthesis of Dihydropyrimidines in Solvent-Free Condition. Synth. Commun. 2004, 34(18), 3335-3341. https://doi.org/10.1081/SCC-200030577.

(26) Ahn, B. J.; Gang, M. S.; Chae, K.; Oh, Y.; Shin, J.; Chang, W. A Microwave-Assisted Synthesis of 3,4-Dihydro-Pyrimidin-2-(1H)-Ones Catalyzed by FeCl3-Supported Nanopore Silica under Solvent-Free Conditions. J. Ind. Eng. Chem. 2008, 14 (3), 401405. https://doi.org/10.1016/j.jiec.2008.01.008.

(27) Pasunooti, K. K.; Chai, H.; Jensen, C. N.; Gorityala, B. K.; Wang, S.; Liu, X. W. A Microwave-Assisted, Copper-Catalyzed Three-Component Synthesis of Dihydropyrimidinones under Mild Conditions. Tetrahedron Lett. 2011, 52(1), 80-84. https://doi.org/10.1016/j.tetlet.2010.10.150.

(28) Changmai, B.; Vanlalveni, C.; Ingle, A. P.; Bhagat, R.; Rokhum, L. Widely Used Catalysts in Biodiesel Production: A Review. RSC Adv. 2020, 10 (68), 41625-41679. https://doi.org/10.1039/d0ra07931f.

(29) Pathak, G.; Das, D.; Rajkumari, K.; Rokhum, L. Exploiting Waste: Towards a Sustainable Production of Biodiesel Using: Musa Acuminata Peel Ash as a Heterogeneous Catalyst. Green Chem. 2018, 20 (10), 2365-2373. https://doi.org/10.1039/c8gc00071a.

(30) Rajkumari, K.; Laskar, I. B.; Kumari, A.; Kalita, B.; Rokhum, L. Highly Selective 
Tetrahydropyranylation/Dehydropyranylation of Alcohols and Phenols Using Porous Phenolsulfonic Acid-Formaldehyde Resin Catalyst under Solvent-Free Condition. React. Funct. Polym. 2020, 149 (January), 104519.

https://doi.org/10.1016/j.reactfunctpolym.2020.104519.

(31) Liu, T.; Li, Z.; Li, W.; Shi, C.; Wang, Y. Preparation and Characterization of Biomass Carbon-Based Solid Acid Catalyst for the Esterification of Oleic Acid with Methanol. Bioresour. Technol. 2013, 133, 618-621. https://doi.org/10.1016/j.biortech.2013.01.163.

(32) Shu, Q.; Gao, J.; Nawaz, Z.; Liao, Y.; Wang, D.; Wang, J. Synthesis of Biodiesel from Waste Vegetable Oil with Large Amounts of Free Fatty Acids Using a Carbon-Based Solid Acid Catalyst. Appl. Energy 2010, 87 (8), 2589-2596.

https://doi.org/10.1016/j.apenergy.2010.03.024.

(33) Laskar, I. B.; Rajkumari, K.; Gupta, R.; Rokhum, L. Acid-Functionalized Mesoporous Polymer-Catalyzed Acetalization of Glycerol to Solketal, a Potential Fuel Additive under Solvent-Free Conditions. Energy and Fuels 2018, 32 (12), 12567-12576. https://doi.org/10.1021/acs.energyfuels.8b02948.

(34) Vasić, K.; Podrepšek, G. H.; Knez, Ž.; Leitgeb, M. Biodiesel Production Using Solid Acid Catalysts Based on Metal Oxides. Catalysts. 2020, 10(2), 237. https://doi.org/10.3390/catal10020237.

(35) Nur Syazwani, O.; Rashid, U.; Taufiq Yap, Y. H. Low-Cost Solid Catalyst Derived from Waste Cyrtopleura Costata (Angel Wing Shell) for Biodiesel Production Using Microalgae Oil. Energy Convers. Manag. 2015, 101, 749-756. https://doi.org/10.1016/j.enconman.2015.05.075.

(36) Changmai, B.; Rano, R.; Vanlalveni, C.; Rokhum, L. A Novel Citrus Sinensis Peel Ash Coated Magnetic Nanoparticles as an Easily Recoverable Solid Catalyst for Biodiesel Production. Fuel 2021, 286, 119447. . https://doi.org/10.1016/j.fuel.2020.119447.

(37) Tan, Y. H.; Abdullah, M. O.; Kansedo, J.; Mubarak, N. M.; Chan, Y. S.; NolascoHipolito, C. Biodiesel Production from Used Cooking Oil Using Green Solid Catalyst Derived from Calcined Fusion Waste Chicken and Fish Bones. Renew. Energy 2019. 
https://doi.org/10.1016/j.renene.2019.02.110.

(38) Semwal, S.; Arora, A. K.; Badoni, R. P.; Tuli, D. K. Bioresource Technology Biodiesel Production Using Heterogeneous Catalysts. Bioresour. Technol. 2011, 102 (3), 21512161. https://doi.org/10.1016/j.biortech.2010.10.080.

(39) Jaliliannosrati, H.; Amin, N. A. S.; Talebian-Kiakalaieh, A.; Noshadi, I. Microwave Assisted Biodiesel Production from Jatropha Curcas L. Seed by Two-Step in Situ Process: Optimization Using Response Surface Methodology. Bioresour. Technol. 2013, 136, 565573. https://doi.org/10.1016/j.biortech.2013.02.078.

(40) Changmai, B.; Laskar, I. B.; Rokhum, L. Microwave-Assisted Synthesis of Glycerol Carbonate by the Transesterification of Glycerol with Dimethyl Carbonate Using Musa Acuminata Peel Ash Catalyst. J. Taiwan Inst. Chem. Eng. 2019, 102, 276-282. https://doi.org/10.1016/j.jtice.2019.06.014. 
